D.O.I.: $10.3895 / \mathrm{S} 1808-04482011000100009$

\title{
PADRONIZAÇÃO HIGIÊNICA - SANITÁRIA EM FRIGORÍFICO DE SUÍNOS, PONTA GROSSA (PR)
}

\section{HYGIENIC AND SANITARY STANDARTIZATION IN PIG SLAUGHERHOUSE, PONTA GROSSA (PR)}

\author{
Renata Louize Samulak ${ }^{1}$; Juliana Vitória Messias Bittencourt ${ }^{2}$; Antonio Carlos de Francisco ${ }^{3}$; Cezar \\ Augusto Romano ${ }^{4}$; Giovana Fanchin Zanetti ${ }^{5}$ \\ ${ }^{1}$ Universidade Tecnológica Federal do Paraná - UTFPR - Ponta Grossa - Brasil \\ renatasamulak@hotmail.com \\ ${ }^{2}$ Universidade Tecnológica Federal do Paraná - UTFPR - Ponta Grossa - Brasil \\ julianavitoria@utfpr.edu.br \\ ${ }^{3}$ Universidade Tecnológica Federal do Paraná - UTFPR - Ponta Grossa - Brasil \\ acfrancisco@utfpr.edu.br \\ ${ }^{4}$ Universidade Tecnológica Federal do Paraná - UTFPR - Ponta Grossa - Brasil \\ caromano@utfpr.edu.br \\ ${ }^{5}$ Universidade Federal do Paraná- UFPR- Curitiba- Brasil \\ gifanchin_z@hotmail.com
}

\begin{abstract}
Resumo
Para que se garanta um alimento com qualidade e segurança alimentar é necessário uniformizar toda a cadeia produtiva desde a obtenção da matéria prima até o produto final. $O$ presente trabalho objetivou padronizar o processo de produção bem como as condições higiênico-sanitárias de um abatedouro com o intuito de melhorar a qualidade do alimento reduzindo custos de produção, garantindo a competitividade das cadeias produtivas de carne. Com este propósito foi avaliado o fluxograma do processo desde a chegada dos animais até a expedição das carcaças, as condições gerais da indústria que contemplam os seguintes itens: localização, vias de acesso interno, infra-estrutura, instalações sanitárias e vestiários, equipamentos, utensílios, instalações para lavagem de mãos e botas, abastecimento de água, controle integrado de pragas e sistema de tratamento de efluentes. Também foram analisados requisitos de higiene ambiental, de equipamentos e utensílios, higiene pessoal, uso de uniformes e equipamentos de proteção individual (EPI's) e ainda feitas verificações sobre a existência de documentações e registros arquivados no estabelecimento. Após apuração das não- conformidades encontradas com o auxílio da lista de verificação da ANVISA, foram tomadas medidas a fim de amenizar os problemas identificados.Foram implantadas ferramentas de gerenciamento da segurança alimentar como a padronização do processo, a implantação de Boas Práticas de Fabricação e elaboração de Procedimentos de Higiene Operacional e a implementação de planilhas de controle e registro. Essas ferramentas foram fundamentais para uniformização e adequação do estabelecimento reduzindo as chances de contaminação garantindo dessa forma maior qualidade microbiológica do produto final.
\end{abstract}

Palavras-chave: padronizar; ferramentas de qualidade; segurança alimentar. 


\section{Introdução}

O mercado de carnes está cada vez mais competitivo e complexo no que se refere ao ciclo de vida e do tempo de prateleira do produto final, além do rigoroso controle higiênico sanitário e da demanda por diversificação e agregação de valor. Para Peloso (2000), a produção de suínos vem deixando de ser uma atividade de suinocultores familiares e passando para grandes operações geralmente controladas pelos sistemas corporativos. Este pode ser um fator determinante na agregação da qualidade desejada pelo consumidor final, cada vez mais consciente e informado sobre os aspectos nutricionais e sanitários das carnes.

Contudo nota-se que a maior parte dos matadouros frigoríficos brasileiros não se encontra em adequadas condições de abate. Segundo Leite et al.(2009), matadouros municipais e de médio e pequeno porte não chegam a atender requisitos mínimos de higiene, não garantindo um produto cárneo livre de contaminação física, química e biológica.

Segundo Toledo (1997), a gestão da qualidade é entendida como a abordagem adotada e o conjunto de práticas utilizadas para obter-se, de forma eficiente e eficaz, a qualidade pretendida para o produto. A gestão da qualidade de uma empresa envolve seus processos e se estende aos fornecedores e clientes.

Para que se garanta a qualidade do produto final e do trabalho das pessoas envolvidas no processo de produção, torna-se necessário a padronização do fluxo de produção do estabelecimento. Esta deve estar de acordo com as normas oficiais e ser realizada por profissionais capacitados, atendendo as normas técnicas para que se assegure a integridade do sistema de qualidade (SILVA, 2006).

A uniformização do processo busca a eficiência e aplicação de padrões que conduzem à simplificação, na medida em que a uniformidade é obtida, reduz a variabilidade e as exceções que complicam o funcionamento de um sistema (GOESE et al., 2006).

A padronização envolve todos os procedimentos de produção, como a obtenção de matéria prima, manejo pré abate e de abate, classificação e tipificação de carcaças, resfriamento, embalagem e transporte. É de fundamental importância que todos esses procedimentos sejam monitorados por planilhas de controle e que os funcionários os quais executam estas atividades sejam freqüentemente treinados. Nesse sentido Ferreira et al. enfatiza a necessidade de constante aperfeiçoamento das ações de controle sanitário na área de alimentos. Isso levou o Ministério da Saúde, dentro da sua competência, a elaborar as portarias 1428 de 26/12/1993 e 326 de 30/7/199712, que estabelecem as orientações necessárias para inspeção sanitária por meio da verificação do Sistema de Análise de Perigo e Ponto Crítico de Controle (APPCC) da empresa produtora e de serviços de alimentos e os aspectos que devem ser levados em conta para a aplicação de boas práticas de fabricação (BPF), respectivamente. 
As condições higiênicas do ambiente de trabalho e o cumprimento das exigências oficiais e legais são fatores importantes na produção e comercialização dos alimentos seguros e de qualidade. A carne por ser um alimento muito perecível, necessita da utilização de métodos de conservação eficientes e eficazes, especialmente após o abate do animal (LUNDGREN et al., 2009).

Segundo Matsubara (2005), as boas práticas de abate reduzem os riscos de contaminação biológica, química e física, elas abrangem todos os requisitos higiênico-sanitários desde instalações, equipamentos, utensílios, condições da matéria- prima, manejo dos animais, requisitos de higiene do ambiente, do manipulador, potabilidade da água utilizada no processo, controle de pragas, manejo de resíduos e tratamento de efluentes.

De acordo com Borch et al. (1996), os animais são os principais geradores da carga microbiana, a partir do conteúdo gastrointestinal, pele, pêlos, região orofaríngea, além dos operadores do ambiente. No processo de abate não há nenhum ponto onde os perigos possam ser eliminados completamente, porém há possibilidade de diminuir a carga microbiana mediante a utilização de ferramentas da qualidade.

A padronização do processamento seja durante a produção, armazenamento ou transporte é um parâmetro importante para se evitar problemas relacionados a toxiinfecções alimentares, por isso a busca pela qualidade assegurada é um fator de destaque na competição das empresas do mercado da carne (RICHARDS, 2003).

O objetivo desse estudo foi padronizar as condições higiênico-sanitárias do abatedouro utilizando como ferramentas de qualidade os manuais de boas práticas de fabricação (BPF) e os procedimentos operacionais padronizados (POP's), com o intuito de melhorar a qualidade do alimento reduzindo custos de produção, garantindo a competitividade das cadeias produtivas de carne.

\section{Metodologia}

\subsection{Local de desenvolvimento da pesquisa}

O presente trabalho foi desenvolvido na região de Ponta Grossa, Paraná em um frigorífico abatedouro de suínos que atua sob Serviço de Inspeção do Paraná (S.I.P) e possui capacidade de abate de cerca de 250 suínos/dia. O processo de abate desse frigorífico segue o fluxograma descrito conforme a figura 1 . 
Figura 1- Fluxograma do Processo

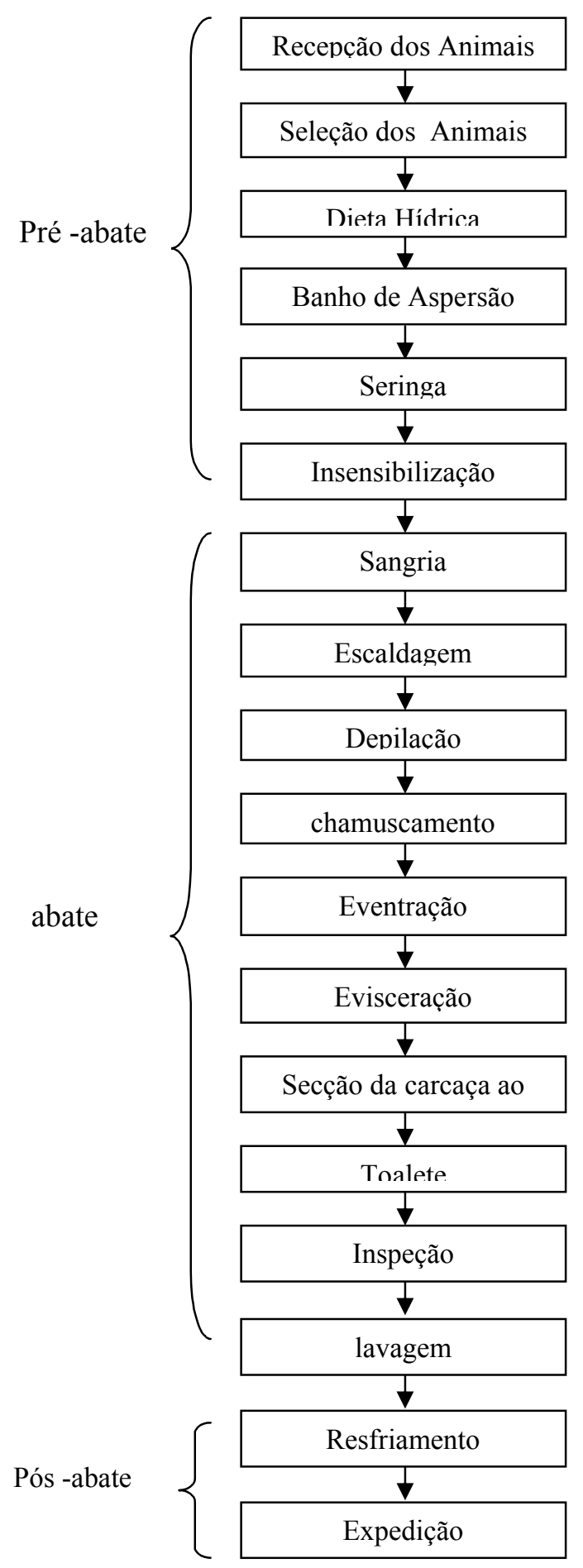

Fonte: Autoria Própria (2010)

\subsection{Estudo de campo}

A pesquisa foi desenvolvida a partir de visitas técnicas ao estabelecimento. Com o auxílio da lista de verificação de Boas Práticas de Fabricação em estabelecimentos produtores/ industrializadores de alimentos da resolução 275/2002, anexo II, da Agência Nacional de Vigilância Sanitária (ANVISA), a partir disto foram identificadas as não- conformidades higiênico-sanitárias existentes no local e então desenvolvidas a padronização higiênico-sanitária do abatedouro. 
Foram observados o fluxograma do processo desde a chegada dos animais até a expedição das carcaças, as condições gerais da indústria que contemplam os seguintes itens: localização, vias de acesso interno, infra-estrutura, instalações sanitárias e vestiários, equipamentos, utensílios, instalações para lavagem de mãos e botas, abastecimento de água, controle integrado de pragas e sistema de tratamento de efluentes.

No que diz respeito aos requisitos de higiene do estabelecimento foram avaliados a higiene: ambiental, de equipamentos e utensílios, higiene pessoal, uso de uniformes e equipamentos de proteção individual (EPI's). Ainda foram averiguados a qualificação dos funcionários e verificado a existência de documentações e registros arquivados no estabelecimento.

\section{Resultados e discussão}

Após avaliação das não- conformidades encontradas com o auxílio da lista de verificação da ANVISA, medidas foram tomadas com o intuito de amenizar os problemas identificados. Para tanto, se viu a necessidade de programar um sistema de controle de qualidade para padronização das operações unitárias que envolvem todo o processo de pré- abate e abate.

Matsubara (2005), afirma que a obtenção de carnes seguras quanto à inocuidade e com boa qualidade tecnológica depende diretamente do processamento dos suínos durante o abate. Para reduzir os riscos de contaminação é necessário estabelecer boas práticas que abrangem todos os requisitos higiênico-sanitários para sua produção.

\subsection{Processo}

O pré-abate se dá desde a chegada dos animais ao frigorífico até a insensibilização. Os animais ao chegarem a indústria devem ser conduzidos para as pocilgas, separados por lotes e por tipo (animais matriz, padrão e refugo). Os animais que apresentarem problemas devem ser colocados em uma pocilga separada denominada pocilga de seqüestro para posterior avaliação do veterinário responsável que deverá caracterizar o problema e registrar em planilha identificando a causa, lote, data e tipo de animal. Os animais sadios devem ficar sob repouso e dieta hídrica durante 16 a 24 horas antes do abate para redução do conteúdo gastrointestinal e diminuição do estresse causado pelo transporte. Foram implantadas planilhas para registro de horário de chegada dos animais para que o tempo de jejum recomendado seja atendido.

A legislação recomenda o banho de aspersão para redução da carga microbiana presente no couro, pois ela pode ser uma fonte de contaminação durante a etapa de abate. A insensibilização do animal é feita com choque elétrico de alta voltagem e baixa amperagem. A Portaria 711/95 determina a aplicação do choque atrás das orelhas do animal (fossas temporais), e tempo entre a insensibilização e sangria não deve exceder 30 segundos evitando assim que o animal recupere a 
consciência. Para Roça e Serrano (1994), o tempo de insensibilização adequado evita o salpicamento hemorrágico garantindo melhor qualidade da carcaça.

As etapas de abate são: sangria, escaldagem, depilação, evisceração, corte e toalete. O pós abate compreende a etapa de refrigeração e expedição. A realização adequada das operações de abate bem como a higienização dos utensílios e do ambiente de trabalho é essencial para garantir a qualidade da carne.

De acordo com Silveira et al. (1996), a sangria deve ser realizada na posição vertical com o animal pendurado pela pata traseira para que o sangue escoe em maior quantidade. Esse procedimento deve ser realizado rapidamente, pois afeta qualidade da carne.

A escaldagem é feita para amolecimento dos pêlos. Foram implantadas planilhas de controle de temperatura da água, temperaturas muito elevadas podem cozinhar a carne e assim comprometer a carcaça. A depilação é feita através de um equipamento denominado depiladeira que retira as cerdas do animal.

Conforme Terra e Fries (2001), inevitavelmente a carcaça entra em contato com o couro, patas, pêlos, utensílios (facas), equipamentos, manipuladores (uniformes), água de lavagem e com o ar do abatedouro. Os equipamentos devem ser sanitizados eficientemente e os uniformes bem higienizados assim como a saúde dos manipuladores deve ser controlada.

Em seguida a carcaça é chamuscada com o auxílio de um lança-chamas, esse procedimento pode queimar a carcaça se realizado de maneira inadequada pelo funcionário.

A evisceração é uma etapa crítica do processo consiste na retirada das vísceras e separação em vermelhas e brancas. Deve-se tomar o cuidado de não perfurar os órgãos evitando assim o extravasamento do conteúdo gastrointestinal. Segundo Terra (1998), perfurar o estômago, intestino ou conteúdo biliar causa contaminação e compromete o consumo da carne. Nessa etapa as vísceras são inspecionadas pelo veterinário responsável. Cabe a ele realizar um exame detalhado e caso seja necessário condenar carcaças que por algum motivo, estiverem comprometidas. Planilhas de controle foram implantadas para facilitar esse procedimento.

Em seguida a carcaça é serrada ao meio, lavada com o auxílio de mangueira, realizado o toalete final, carimbada e então segue para as câmaras- frias onde é resfriada a uma temperatura inferior a com o intuito de evitar a proliferação de microorganismos diminuindo o tempo de vida de prateleira da carne. A temperatura das câmaras frias bem como o tempo de resfriamento deve ser monitorada.

A legislação estabelece que a câmara-fria esteja com temperatura média de $0^{\circ} \mathrm{C}$ e que a temperatura no interior da carcaça deve atingir $7^{\circ} \mathrm{C}$ num período entre 18 a 24 horas. Para isso planilhas de controle foram elaboradas. O controle de resfriamento da carcaça define a qualidade 
final dos cortes com relação aos parâmetros físico-químicos e microbiológicos aumentando assim o tempo de vida de prateleira da carne (ROÇA; SERRANO, 1994).

A expedição também deve ser padronizada e monitorada, a temperatura em que se encontra a carcaça e a temperatura do caminhão de transporte devem estar adequadas e registradas para monitoramento da etapa.

Todas as etapas do processo elencadas acima, desde a chegada dos animais até a expedição, foram padronizadas e descritas no manual de boas práticas elaborado para o estabelecimento. Os procedimentos operacionais padronizados foram desenvolvidos com o intuito de uniformizar as operações unitárias de abate para que sejam realizadas de maneira satisfatória e garantam a qualidade e a integridade do produto final.

Segundo Goese et al. (2006), a abordagem da padronização de processos é uma forma eficaz de se organizar e gerenciar a maneira como as atividades da empresa agregam valor. Necessário é identificar os processos para melhorias e compreensão do negócio. Desenvolver um sistema que permita a mensuração e diagnóstico da situação presente, prever acontecimentos futuros e permitir ações como o planejamento e controle de padronização dos processos organizacionais são fundamentais para o desenvolvimento de estratégias que tragam alguma vantagem competitiva. Nesse sentido, planilhas foram implantadas conforme mostra a tabela 1.

Tabela 1- Planilhas de controle de processo

\begin{tabular}{|c|c|c|c|c|}
\hline & Etapa & Nome da Planilha & Preenchimento de dados & Periodicidade \\
\hline \multirow{3}{*}{$\begin{array}{l}\text { Pré- } \\
\text { Abate }\end{array}$} & $\begin{array}{l}\text { Recepção/Seleção } \\
\text { dos animais }\end{array}$ & $\begin{array}{l}\text { Controle de recebimento } \\
\text { de animais }\end{array}$ & $\begin{array}{c}\text { Lote, data, horário de } \\
\text { chegada, quantidade total } \\
\text { de animais e quantidade } \\
\text { por tipo (matriz, padrão, } \\
\text { refugo) }\end{array}$ & $\begin{array}{c}\text { A cada lote } \\
\text { descarregado }\end{array}$ \\
\hline & $\begin{array}{l}\text { Identificação de } \\
\text { Animais com } \\
\text { problema }\end{array}$ & Planilha de seqüestro & $\begin{array}{l}\text { Lote, data, tipo de animal, } \\
\text { problema identificado, } \mathrm{n}^{\circ} \\
\text { total de animais com } \\
\text { problema por lote }\end{array}$ & $\begin{array}{c}\text { A cada lote } \\
\text { descarregado }\end{array}$ \\
\hline & Insensibilização & $\begin{array}{l}\text { Controle de manutenção } \\
\text { e calibração de } \\
\text { equipamentos (choque } \\
\text { elétrico) }\end{array}$ & $\begin{array}{c}\text { Data, tipo de manutenção } \\
\text { ( preventiva/ emergência), } \\
\text { problema identificado }\end{array}$ & $\begin{array}{l}\text { Semanalmente } \\
\text { ou quando } \\
\text { houver } \\
\text { necessidade }\end{array}$ \\
\hline \multirow[b]{2}{*}{ Abate } & Escaldagem & $\begin{array}{l}\text { Controle de temperatura } \\
\text { do tanque de escaldagem }\end{array}$ & $\begin{array}{c}\text { Data, temperatura } 1, \\
\text { temperatura } 2\end{array}$ & $\begin{array}{l}2 \text { tomadas de } \\
\text { temperatura }\end{array}$ \\
\hline & Evisceração & Planilhas do SIP/POA & $\begin{array}{l}\text { Devem ser preenchidas } \\
\text { pelo veterinário da } \\
\text { inspeção }\end{array}$ & $\begin{array}{l}\text { Sempre que } \\
\text { houver abate }\end{array}$ \\
\hline \multirow{3}{*}{$\begin{array}{l}\text { Pós } \\
\text { abate }\end{array}$} & \multirow[t]{2}{*}{ Resfriamento } & $\begin{array}{l}\text { Planilha de controle de } \\
\text { temperatura de câmara- } \\
\text { fria }\end{array}$ & $\begin{array}{l}\text { Data, temperatura } 1, \\
\text { temperatura } 2, \\
\text { temperatura } 3,\end{array}$ & $\begin{array}{l}\text { Diariamente } \\
\text { fazer } 3 \\
\text { tomadas de } \\
\text { temperatura }\end{array}$ \\
\hline & & $\begin{array}{c}\text { Planilha de controle de } \\
\text { temperatura do interior } \\
\text { da carcaça }\end{array}$ & $\begin{array}{l}\text { Data, horário de entrada, } \\
\text { horário de saída, } \\
\text { temperatura da carcaça }\end{array}$ & $\begin{array}{l}\text { A cada lote que } \\
\text { for armazenado } \\
\text { na câmara fria }\end{array}$ \\
\hline & Expedição & $\begin{array}{l}\text { Controle de temperatura } \\
\text { do caminhão }\end{array}$ & $\begin{array}{c}\text { Data, horário e } \\
\text { temperatura do caminhão }\end{array}$ & $\begin{array}{l}\text { Sempre que } \\
\text { houver }\end{array}$ \\
\hline
\end{tabular}




\begin{tabular}{cccc}
\hline & & carregamento \\
\hline Todas as etapas & $\begin{array}{c}\text { Planilha de controle de } \\
\text { temperatura de } \\
\text { esterilizadores }\end{array}$ & $\begin{array}{c}\text { Data, temperatura 1, } \\
\text { temperatura 2 }\end{array}$ & $\begin{array}{c}\text { Durante abate } \\
2 \text { tomadas de } \\
\text { temperatura }\end{array}$ \\
\hline
\end{tabular}

Fonte: Autoria Própria (2010)

Silva (2004), afirma que a probabilidade de contaminação da carne durante o processo de abate é alta, por isso a necessidade de praticar procedimentos corretos e padronizados, prevenindo assim a contaminação cruzada com higiene permanente e controle minucioso dos pontos considerados críticos.

\subsection{Condições gerais do frigorífico}

A localização não está de acordo com as normas da legislação, pois existem lugares sujeitos a inundações devido à existência de rio próximo ao estabelecimento também ofereciam risco de proliferação de pragas pelo acúmulo de materiais em desuso. As vias de acesso interno propiciavam o acúmulo de água empoçada. De acordo com a Portaria 368/97 do Ministério da Agricultura, Pecuária e Abastecimento os estabelecimentos deverão estar situados, preferivelmente, em zonas isentas de odores indesejáveis, fumaça, poeira e outros contaminantes, e que não estejam expostas a inundações e as vias internas e áreas utilizadas pelo estabelecimento, que se encontram dentro do seu limite perimetral, deverão ter uma superfície compacta e/ou pavimentada, apta para o tráfego de veículos. Devem possuir escoamento adequado, assim como meios que permitam a sua limpeza. Partindo desse contexto houve a necessidade de retirar os materiais em desuso e recobrir o terreno com brita para minimizar os riscos de contaminação.

A infra-estrutura do local estava necessitando de manutenção. Para que uma indústria de alimentos atendam as condições higiênico-sanitárias desejáveis é preciso que sua construção facilite a higienização evitando assim a proliferação de microorganismos.

A parede, tetos devem ser laváveis, impermeáveis e lisos assim como o piso que deve possuir declividade de $2 \%$ evitando o empoçamento de água e com cantos abaulados com o intuito de impedir acúmulo de sujidades e possível formação de biofilmes. As janelas devem ser revestidas com telas e os ralos devem possuir protetores a fim de evitar a passagem de pragas e vetores. As instalações elétricas devem ser revestidas com protetores. O fluxo deve ser contínuo para impedir a contaminação cruzada (BRASIL, 1995).

Os equipamentos e utensílios devem ser constituídos de material de fácil limpeza. A madeira, amianto e matérias rugosos e porosos devem ser evitados, pois propiciam a proliferação microbiana. A manutenção é fundamental para uniformização do processo. Nesse sentido planilhas de calibração e manutenção preventiva foram implantadas. 
É fundamental a existência de barreiras sanitárias, para impedir que microorganismos sejam levados para dentro da área de produção, como o pedilúvio, lavadores de botas e pias para lavagem das mãos que devem possuir soluções detergentes e sanitizantes (SILVA, 2006).

As instalações sanitárias devem possuir lavatórios e dispor de produtos destinados à higiene pessoal como sabonete líquido inodoro anti-séptico, papel higiênico e toalhas de papel nãoreciclados (BRASIL, 1997).

O estabelecimento deve ser abastecido com água potável e possuir número de reservatórios compatíveis com a demanda. Para garantir a qualidade da água, a cloração deve ser controlada e análises microbiológicas realizadas trimestralmente. As caixas de água também devem ser higienizadas com freqüência (BRASIL, 2002). Para monitoramento do sistema de abastecimento de água planilhas foram implantadas.

O controle integrado de pragas são ações que reduzem e impedem a presença de insetos, roedores no perímetro da indústria e geralmente é realizado por empresas terceirizadas. Esse controle garante a redução de riscos de contaminação biológica. A resolução RDC n 18 de 29 de fevereiro de 2000, dispõe sobre Normas Gerais para funcionamento de Empresas Especializadas na prestação de serviços de controle de vetores e pragas urbanas. Esta norma tem como objetivo estabelecer diretrizes, definições e condições gerais para o funcionamento das Empresas Especializadas controladoras de pragas urbanas, visando o cumprimento das Boas Práticas Operacionais, a fim de garantir a qualidade e segurança do serviço prestado e minimizar o impacto ao ambiente, à saúde do consumidor e do aplicador (BRASIL, 2000).

O sistema de tratamento de efluentes do abatedouro é constituído por caixas retentoras de gordura e lagoas de tratamento. Foi verificado que existe acompanhamento por empresas terceirizadas que realizam a manutenção e fazem análises periódicas, porém não foram encontradas planilhas de controle efetivo desse procedimento. Segundo Scarassati et al. (2003), é importante realizar o tratamento, pois os efluentes são agentes poluidores das águas em ameaça à saúde pública.

\subsection{Condições higiênico-sanitárias}

Foi observada a inexistência de procedimentos padronizados de higiene. Para tanto foi implementado um gerenciamento de segurança alimentar utilizando como ferramenta os procedimentos de higiene operacional. De acordo com PROFIQUA (1995), as etapas de higienização geral (área de produção) de equipamentos e utensílios que consistem em:

- Remoção dos resíduos- consiste na limpeza grosseira dos resíduos em contato com a superfície com auxílio de abrasivos físicos;

- $\quad$ Pré- lavagem- remoção utilizando apenas água preferencialmente morna; 
- $\quad$ Lavagem - remoção dos resíduos pelo uso de soluções detergentes;

- $\quad$ Enxágüe- remoção da solução detergente utilizando água;

- Sanificação- Redução de microorganismos pelo uso de solução sanificante com tempo de contato de 10-15 minutos;

- $\quad$ Enxágue- Remoção da solução sanificante quando necessário.

Foi estabelecida a periodicidade de higienização de acordo com o tipo de superfície a ser higienizada como mostra a tabela 2. Para determinação dessa freqüência observou-se o risco de contaminação oferecido por cada local bem como a possível formação de biofilmes.

Tabela 2- Periodicidade de higienização

\begin{tabular}{lc}
\hline \multicolumn{1}{c}{ Local } & Periodicidade \\
\hline Bancadas, equipamentos, utensílios, mesas de apoio & Após o uso \\
-pisos, rodapés e ralos; & Diário \\
-todas as áreas de lavagem e de produção, maçanetas, lavatórios (pias); & Semanal \\
-sanitários cadeiras e mesas; monoblocos e recipientes de lixo; & Quinzenal \\
-Paredes na altura das bancadas & Mensal \\
Paredes, portas, janelas, prateleiras (armários), coifa, geladeiras, câmaras e freezers & Semestral \\
\hline
\end{tabular}

Fonte: Adaptado de Silva (1996)

Com relação à higiene pessoal foi relatada pela direção do estabelecimento a necessidade de orientação aos funcionários com relação a esse requisito, pois nunca houve treinamento adequado. Segundo Silva (1996), a higiene pessoal é um dos requisitos mais importantes relacionado à higiene de alimentos, pois o homem é direta ou indiretamente responsável pela contaminação de alimentos durante a manipulação. Para solucionar o problema, foram propostos treinamentos referentes a higiene correta de mãos, uso de uniformes e EPI's aos funcionários.

Gamarra (2007) reforça a necessidade dos cuidados higiênico-sanitários que os funcionários devem ter e o cumprimento dos procedimentos de controle da qualidade em todas as etapas do abate para evitar a contaminação cruzada.

\subsection{Registros e documentos}

Não foi identificado no abatedouro nenhum tipo de documentação como Manuais de Boas Práticas, Procedimentos Operacionais Padronizados (POP's) e Procedimentos de Higiene Operacional (PPHO’s), Planilhas de registro de todo o processo. Esses documentos são ferramentas de gestão da segurança alimentar, pois ajudam a diminuir os riscos de contaminação durante a produção do alimento. São inúmeras as vantagens da implantação destes programas, dentre elas 
podemos enumerar a adequação à legislação vigente, obtenção de alimentos seguros, satisfação do consumidor e redução de gastos com produtos recolhidos do mercado (MICHALCZYSZYN et al., 2008).

Partindo desse contexto houve a necessidade de elaboração e implantação de tais ferramentas para que o estabelecimento pudesse dar início ao processo de uniformização através do estabelecimento de procedimentos padrões em conformidade com as exigências da legislação vigente, descritos e documentados sob a forma de manuais. As planilhas de registro visam controlar de forma rotineira a correta execução das atividades descritas nos manuais. A partir desse controle é possível evitar a contaminação direta ou cruzada e a adulteração do produto, preservando dessa forma a integridade do alimento.

\subsection{Capacitação dos funcionários}

Segundo relatado pela alta direção do frigorífico, a maioria dos funcionários contratados não apresentam qualificação. A grande rotatividade de operários, comum em atividades de abate, acarreta dificuldade de contratação de mão de obra capacitada, que interfere diretamente na implantação da padronização do processo, pois essa padronização depende da atuação correta do funcionário.

Goese et al. (2006), acredita que muitas vezes, o mau desempenho de um operário é causado por força reflexiva de outro colega, do responsável pelo setor, ou da política da empresa em não reconhecer e valorizar os seus recursos humanos. Entre outros, o autor cita: o trabalho não é distribuído eqüitativamente, alguns funcionários ficam sobrecarregados, tendo até que fazer horas extras e outros ociosos, colaboradores executando tarefas superiores ou inferiores à sua capacitação profissional.

Além disso, os manipuladores de alimentos têm importante papel na veiculação de microorganismos para o alimento manipulado, porém, na maioria das vezes não são treinados para os princípios de suas funções ignorando princípios de higiene e boas atitudes de trabalho. A finalidade do treinamento de manipuladores é possibilitar-lhes princípios teóricos e práticos a fim de capacitá-los para executar atividades na área de alimentos (ANDREOTTI, 2003).

Para minimizar o problema da falta de qualificação de mão de obra, palestras e treinamentos relativos aos procedimentos de abate, limpeza e higienização foram ministradas aos funcionários da produção. O treinamento deve ser periódico, pois não é possível realizar mudanças estruturais sem que haja colaboração constante por parte dos funcionários (FIGUEIREDO; COSTA NETO, 2001).

A uniformidade das etapas do processo desde a chegada da matéria-prima até a expedição incluindo a higienização da estrutura, equipamentos e utensílios auxilia na organização da empresa de forma eficaz, tornando um diferencial imprescindível em relação a concorrência, aumentando 
dessa forma a competitividade no mercado pois o estabelecimento oferece ao consumidor um produto com qualidade assegurada.

De acordo com Toledo et al. (2000), apesar das empresas agro alimentares brasileiras reconhecerem a importância da inspeção e da padronização dos processos, pouco compreendem ou exploram a gestão da qualidade de maneira estratégica, ou seja, como forma de melhoria na competitividade da empresa por meio da satisfação dos clientes, diferenciando seus produtos no atributo qualidade.

A padronização dos processos ajuda no controle dos processos, a qualificação e desenvolvimento da equipe e aplicação de tecnologias, que gera um padrão de qualidade reconhecido pelos clientes, reduzindo as incertezas quanto à satisfação de suas expectativas e possibilita uma melhor utilização dos seus recursos e conseqüentemente a redução dos custos (GOESE et al., 2006).

\title{
4. Conclusão
}

A padronização higiênico-sanitária do abatedouro com o auxílio de ferramentas de gerenciamento de segurança alimentar, como os manuais de boas práticas de fabricação e os procedimentos operacionais padronizados se fez necessária para garantir a uniformidade do processo produtivo resultando em qualidade e segurança da carne produzida e comercializada, redução de desperdícios e aumento dos lucros além de proporcionar ao estabelecimento maior competitividade no setor de carnes e facilitar um futuro processo de certificação dos seus produtos.

\begin{abstract}
To ensure that a food quality and food safety is necessary to standardize the entire production chain from the acquisition of raw material to finished product. This study aimed to standardize the production process and the sanitary conditions of a slaughterhouse in order to improve food quality by reducing production costs, ensuring the competitiveness of meat production chains. With this purpose we have evaluated the process flowchart since the arrival of the animals to the carcasses shipment, the general conditions of the industry which include the following items: location, internal access roads, infrastructure, toilets and changing facilities, equipment, utensils facilities for washing hands and boots, water, integrated pest management and effluent treatment system. Were also analyzed environmental hygiene requirements, equipment and utensils, personal hygiene, uniforms usage and personal protective equipment (PPE) and also made checks on the documentation existence and records filed in the establishment. After nonconformities found counting using the ANVISA checklist, measures were taken to mitigate identified problems. Management tools of food security were implemented as the standardization process, the implementation of Good Manufacturing Practices and Procedures development and implementation of Hygiene Operational control sheets and registration. These tools were fundamental to establishing uniformity and appropriateness of reducing the contamination chances thereby ensuring greater microbiological quality of the final product.
\end{abstract}

Key-words: standardize; quality tools; safety food.

\section{Referências}

ANDREOTTI, A.; BAlERONI, F. H.; PAROSCHI, V. H. B.; PANZA, S. G. A. Importância do treinamento para manipuladores de alimentos em relação a higiene pessoal. Iniciação Científica. Cesumar, vol. 05, n.01, p.29-33. janjun., 2003. 
BORCH, E.; NESBASKKEN, T.; CHRISTEN, H. Harzard identification in swine slaughter with respect to foodborn bacteria. International Journal of Food Microbiology, v.30, p. 9-25, 1996.

cross ${ }^{\text {ref }}$

BRASIL. Ministério da Agricultura, Pecuária e Abastecimento. Portaria N 368, de 4 de setembro de 1997: aprova o Regulamento Técnico sobre as Condições Higiênico-sanitárias e Boas Práticas de Elaboração para estabelecimentos Elaboradores/ Industrializadores de Alimentos. Diário Oficial da União, Brasília, Seção I, p. 19697-19699, 8 set 1997a.

Ministério da Agricultura, Pecuária e Abastecimento. Portaria No 711, Normas Técnicas de Instalações e Equipamentos de Abate e Industrialização de Suínos, de $1^{\circ}$ de Novembro de 1995. Diário Oficial da União, Brasília, Seção I, p. 17625, 03 nov. 1995.

Ministério da Saúde. Secretaria de Vigilância Sanitária. Regulamento Técnico de Procedimentos Operacionais Padronizados aplicados aos Estabelecimentos Produtores/Industrializadores de Alimentos e a Lista de Verificação das Boas Práticas de Fabricação em Estabelecimentos Produtores/Industrializadores de Alimentos. Resolução ${ }^{\circ} 275$, de 21 de outubro de 2002. Diário da União, Brasília, 06 de Nov. 2002.

Ministério da Saúde. Agência Nacional de Vigilância Sanitária. Normas Gerais para funcionamento de Empresas Especializadas na prestação de serviços de controle de vetores e pragas urbanas. Resolução RDC $\mathrm{n}^{\circ} 18$, de 29 de fevereiro de 2000. Diário da União, 03 de Mar. 2000.

Ministério da Saúde. Secretaria de Vigilância Sanitária. Portaria no 326, de 30 de julho de 1997. Regulamento Técnico sobre as Condições Higiênico-Sanitárias e de Boas Práticas de Fabricação para Indústrias de Alimentos. Diário oficial da União, Brasília, 01 ago. 1997b.

Ministério da Saúde. Secretaria de Vigilância Sanitária. Portaria n ${ }^{0} 1.428$, de 26 de novembro de 1993. Regulamentos Técnicos sobre Inspeção Sanitária, Boas Práticas de Produção/Prestação de Serviços e Padrão de Identidade e Qualidade na Área de Alimentos. Diário Oficial da União, Brasília, Sec. I. p. 18415-18419, 02 dez. 1993.

FERREIRA, C. E. M.; BEZERRA, L. G.; NETO, G. V. Guia para implantação de boas práticas de fabricação (BPF) e do Sistema APPCC. Rio de Janeiro, 2001.

FIGUEIREDO, V. F.; COSTA NETO, P. L. O. Implantação de HACCP na indústria de Alimentos. Rev. Gestão \& Produção, v.8, n.1, p.100-111, abr. 2001.

crossef

GAMARRA, R. M. Identificação de Pontos Críticos para Salmonella spp no abate de suínos. 53p. Dissertação (Mestrado). Universidade Federal de Santa Maria, Programa de Pós-graduação em Ciência e Tecnologia de Alimentos, Rio Grande do Sul, 2007.

GOESE, I. B.; BRAGATO, L. L.V.; PEREIRA, N. N. A padronização dos processos: uma ferramenta gerencial. Universo Acadêmico, n. 09. Jan- jun, 2006.

LEITE, A. I. et al. Condições Físicas e Higiênico - Sanitárias dos Matadouros.

Municipais da região Oeste do Rio Grande Do Norte, Brasil. Arquivo Instituto. Biologia, São Paulo, v.76, n.3, p.335340, jul./set., 2009.

MATSUBARA, E. N. Condição higiênica - sanitária de meias carcaças de suínos após o abate e depois do resfriamento e análise de utilização de Lista de Verificação para avaliar boas práticas no abate de suínos.152p. Dissertação (Mestrado) Universidade de São Paulo, Faculdade de Zootecnia, São Paulo, 2005.

MICHALCZYSZYN, M.; GIROTO, J. M.; BORTOLOZO, E. Q. Avaliação e Certificação em Boas Práticas de Fabricação de uma empresa de alimentos orgânicos no município de Ponta Grossa, PR - estudo de caso. Revista Higiene Alimentar. São Paulo, v. 22, n. 159, p. 33-35, mar. 2008.

PELOSO, J. V. Tratamento pós-abate das carcaças e os desvios de qualidade na transformação músculo-carne em suínos. $1^{\text {a }}$ Conferência Internacional Virtual sobre Qualidade de Carne Suína. Embrapa, Concórdia, Santa Catarina, 2001 p.100-108. 
RICHARDS, N. S. P. S. Segurança Alimentar- Como prevenir contaminações na indústria. Food Ingredients. p. 16-30, 2003.

ROÇA, R.O.; SERRANO, M. A. Operações de abate. Rev. Higiene Alimentar, v. 8, n.34, 1994.

SCARASSATI, D. et al. Tratamento de Efluentes de Matadouros Frigoríficos. III Fórum de Estudos Contábeis, 2003.

SILVA, L. F. Procedimento Operacional Padronizado de Higienização como Requisito para Segurança Alimentar em Unidade de Alimentação. 2006. Dissertação (Mestrado). Universidade Federal de Santa Maria, Rio Grande do Sul, 2006.

SOCIEDADE BRASILEIRA DE CIÊNCIA E TECNOLOGIA DE ALIMENTOS - SBCTA. Manual sobre Qualidade- PROFIQUA. Higienização e Sanitização para empresas de alimentos. 1ª Ed, São Paulo- SP, 1995.

SILVA, L. E. Infecção por Salmonella spp em suínos. Suinocultura em foco - Favet - UFRGS. Ano IV n.11, p.4-5, Abril/ Maio/ Junho, 2004.

SILVEIRA, E. T. F. O Bem Estar Animal e a Industrialização da Carne Suína. Simpósio Internacional "O Bem Estar dos Animais destinados à Produção de Produtos Cárneos, 11, 1996. Santa Maria. Anais... Universidade Federal de Santa Maria, 1996.

TERRA, N. N. Apontamentos de Tecnologias de Carnes. São Leopoldo: Editora Unisinos, 1998.

TERRA, N. N.; FRIES, L. L. M. A qualidade da carne suína e sua industrialização. 1a Conferência Internacional Virtual sobre Qualidade de Carne Suína, Embrapa, Concórdia, Santa Catarina, 2001. p.147-151.

TOLEDO, J. C. Gestão da qualidade na agroindústria. In: Batalha, M. O. Gestão agroindustrial. São Paulo: Atlas, 1997. v. 1, cap. 8 .

TOLEDO, J. C. Qualidade na Indústria Agroalimentar: Situação Atual e perspectivas. Revista de administração de Empresas, v. 40, p. 90-101. Abr/jun 2000.

\section{Nome completo: Renata Louize Samulak}

Filiação institucional: Universidade Tecnológica Federal do Paraná- UTFPR

Função ou cargo ocupado: aluna de especialização em Gestão Industrial: Conhecimento e Inovação Endereço completo para correspondência (bairro, cidade, estado, país e CEP): Rua Dr. Joaquim de Paula Xavier, 460. Jardim América. Ponta Grossa, PR, BRASIL. CEP 84050-000

Telefones para contato: (42) 9913-2166

e-mail:renatasamulak@hotmail.com

\section{Nome completo: Juliana Vitória Messias Bittencourt}

Filiação institucional: Universidade Tecnológica Federal do Paraná- UTFPR

Departamento: Engenharia de Produção

Função ou cargo ocupado: professora doutora

Endereço completo para correspondência (bairro, cidade, estado, país e CEP): Universidade Tecnológica Federal do Paraná, Campus Ponta Grossa. Av: Monteiro Lobato s/n km 4 .CEP: 84016-210 - Ponta Grossa, PR - Brasil - Caixa-Postal: 157

Telefones para contato: (42) 4232204823 
Nome completo: Antônio Carlos de Francisco

Filiação institucional: Universidade Tecnológica Federal do Paraná- UTFPR

Departamento: Departamento de Pós Graduação

Função ou cargo ocupado: Professor doutor

Endereço completo para correspondência (bairro, cidade, estado, país e CEP): Av. Monteiro

Lobato, Km 04. CEP 84016-210 - Ponta Grossa, PR - Brasil - Caixa-Postal: 20

Telefones para contato: Fone: (42) 32204876 Fax: (42) 32204805

e-mail: acfrancisco@utfpr.edu.br

Nome completo: Cezar Augusto Romano

Filiação Institucional: Universidade Tecnológica federal do Paraná- UTFPR

Departamento: Departamento acadêmico de Construção Civil

Função ou cargo ocupado: professor doutor

Endereço completo para correspondência (bairro, cidade, estado, país e CEP): Avenida Sete de

Setembro no 3.165, Rebouças. CEP: 80230-901 - Curitiba, PR - Brasil

Telefones para contato: (41) 3310-4600/(41) 33104603

e-mail: caromano@utfpr.edu.br

Nome completo: Giovana Fanchin Zanetti

Filiação institucional: Universidade Federal do Paraná- UFPR

Departamento: Ciências Agrárias

Função ou cargo ocupado: aluna de mestrado em Ciências Veterinárias

Endereço completo para correspondência (bairro, cidade, estado, país e CEP): Rua Xavier da Silva, 440. Ap. No 42. CEP 84010-250. Ponta Grossa, PR, Brasil

Telefones para contato: (42) 3224-2231/ (42) 8835-0095

e-mail:gifanchin_z@hotmail.com

Enviado em: 09/06/2010

Aprovado em: 28/02/2011 